Revista Brasileira de Agricultura Irrigada v.7, nº. 6, p. 381 - 389, 2013

ISSN 1982-7679 (On-line)

Fortaleza, CE, INOVAGRI - http://www.inovagri.org.br

DOI: $10.7127 /$ rbai.v7n600181

Protocolo 181.13 - 20/09/2013 Aprovado em 27/11/2013

\title{
INFLUÊNCIA DA IRRIGAÇÃO NA PRODUTIVIDADE DA ROSEIRA CULTIVADA EM AMBIENTE PROTEGIDO
}

José Aglodoaldo Cavalcante Júnior ${ }^{1}$, Benito Moreira de Azevedo ${ }^{2}$, Geocleber Gomes de Sousa ${ }^{3}$, Thales Vinicius de Araújo Viana ${ }^{2}$, Denise Vieira Vasconcelos ${ }^{4}$, Lais Monique Gomes do Ó 5

\section{RESUMO}

O crescimento da floricultura cearense deve-se, principalmente, ao uso adequado de da irrigação em ambiente protegido. O objetivo deste trabalho foi avaliar os efeitos de diferentes níveis de irrigação nos aspectos produtivos da cultura da roseira (Rosa $s p$ ) cultivada em ambiente protegido. $\mathrm{O}$ experimento foi conduzido no Comercio Exportação Importação e Produção de Flores (CEAROSA), localizada no Distrito de Inhuçú, São Benedito, Ceará, Brasil, no período de setembro a dezembro de 2005. A variedade de roseira avaliada no experimento foi a Iracema. No experimento foram estudadas cinco lâminas de irrigação correspondente a: 100; 150; 200; 250 e 300\% da evaporação de água observada em um tanque Reduzido (ETR). O delineamento experimental foi de blocos ao acaso, com cinco tratamentos e cinco repetições. Foram analisadas as seguintes variáveis de produtividade: Top Quality (TQ), Carmela Diamante (CD), Carmela Ouro (CO) e total. Dentre as lâminas de irrigação testadas, a de $200 \%$ da evaporação de água no tanque Reduzido foi a menor lâmina que proporciona o maior rendimento da roseira, obtendo-se uma produtividade de 288.750 (hastes $\mathrm{ha}^{-1}$ ciclo $^{-1}$ ). A lâmina de irrigação correspondente a $263 \%$ da evaporação de água no tanque Reduzido foi calculada a máxima produtividade $\left(354,381\right.$ hastes $\left.^{-1} \mathrm{ciclo}^{-1}\right)$.

Palavras-chave: floricultura, manejo da irrigação, casa de vegetação

\footnotetext{
${ }^{1}$ Engenheiro Agrônomo, Doutor em Engenharia Agrícola, Professor, Instituto Federal de Educação, Ciência e Tecnologia - Câmpus Crateús. Rua Lopes Vieira S/N. - Venâncios, CEP: 63700 - 000. Crateús - CE. Email: cavalcante_junior@hotmail.com

${ }^{2}$ Engenheiro Agrônomo, Doutor em Engenharia Agrícola, Departamento de Professor Engenharia Agrícola, Universidade Federal do Ceará, Campus do Pici, Av. Mister Hull, 2977, CEP 60455-760, Fortaleza, CE. Email:benitoazevedo@hotmail.com; thales@ufc.br

${ }^{3}$ Engenheiro Agrônomo, Doutor em Engenharia Agrícola, bolsista de PNPD/CAPES/UFC, Universidade Federal do Ceará, Campus do Pici, Av. Mister Hull. E-mail:sousasolosgeo@ hotmail.com

${ }^{4}$ Engenheira Agrônoma, Doutora em Engenharia Agrícola Universidade Federal do Ceará, Campus do Pici, Av. Mister Hull. E-mail: denisevasconcelos@ hotmail.com

${ }^{5}$ Graduanda em Agronomia, bolsista de PIBIc, Universidade Federal do Ceará, Campus do Pici, Av. Mister Hull. E-mail: laisnique@ hotmail.com
} 


\title{
INFLUENCE OF IRRIGATION ON THE PRODUCTIVITY OF ROSE GROWN IN THE GREENHOUSE
}

\begin{abstract}
The growth of floriculture Ceará is due, mainly, to the proper use of irrigation in greenhouse. The aim of this study was to evaluate the effects of different irrigation levels on productive aspects of the culture of rose (Rosa sp) cultivated in a greenhouse. The experiment was conducted at CEAROSA Comércio Exportação Importação e Produção de Flores LTDA, located in the Inhuçú District, São Benedito, Ceará (state), Brazil, from September to December 2005. A variety of rose evaluated in the experiment was the Iracema. In the experiment we studied five irrigation corresponding to: 100, 150, 200, 250 and $300 \%$ of water evaporation observed in a tank Reduced (ETR). The experimental design was randomized blocks with five treatments and five replications. We analyzed the following variables productivity: Top Quality (TQ), Carmela Diamond (CD), Carmela Golden (CO), total. Among the irrigation tested at $200 \%$ of evaporation of water in the tank was lowered to the lower blade provides the greatest yield rose to give a yield of 288.750 (cycle rods $\mathrm{ha}^{-1}$ ). The irrigation corresponding to $263 \%$ of evaporation of water in the tank was lowered calculated maximum yield ( 354.381 cycle rods ha $^{-1}$ ).
\end{abstract}

Keywords - floriculture, irrigation management, greenhouse

\section{INTRODUÇÃO}

A roseira é uma planta perene, arbustiva, com hábito de crescimento ereto, trepador ou reptante, caule lenhoso apresentando ou não espinhos. As folhas são pinadas, caducas, disposta de forma alternada e compostas de cinco a sete folíolos ovalados. Emite ramos basais na primavera e em condições de casa de vegetação, onde a temperatura é mais alta. Os ramos basais são mais grossos, permitindo a planta formar seu esqueleto e produzir hastes florais para comercialização. As flores se desenvolvem no ápice das hastes, de forma solitária ou em cacho, contendo normalmente cinco sépalas com lóbulos laterais e fruto do tipo aquênio (BAÑON ARIAS et al., 1993; BARBOSA, 2003).

No mercado mundial, a floricultura está em plena expansão e tem como principal exportador a Holanda, seguida por Colômbia e Itália. O Brasil ainda apresenta pouca expressão no segmento mundial. Entretanto, esta participação vem se expandindo ao longo dos últimos anos.

O setor de floricultura brasileiro conta atualmente com quatro mil produtores, concentrados, principalmente, em São Paulo (70\% da produção), Minas Gerais, Rio de Janeiro, Alagoas, Pernambuco, Bahia, Ceará, Rio Grande do Sul e Santa Catarina. Estima-se que hoje existam cerca de 10 mil pontos de venda, 400 atacadistas em uma dezena de centros atacadistas, gerando 120 mil empregos. Atualmente a atividade vem crescendo cerca de $20 \%$ ao ano (GAVIOLI, 2004).

O Ceará é o segundo maior expor- 
tador de flores do Brasil, atrás apenas de São Paulo. A área plantada, no setor de floricultura, aumentou de 19 hectares em 1999, para 260 hectares em 2006, representando um crescimento de 1,268\% (SEAGRI, 2006).

O crescimento da floricultura cearense deve-se, principalmente, ao uso adequado de tecnologias e cultivo protegido, ampliação da área cultivada e uma política agressiva de marketing. O mercado mundial de flores e plantas ornamentais está em plena expansão e tem como principal exportador a Holanda, seguida pela Colômbia e Itália. O Brasil tem tido uma participação crescente, mas ainda pouco expressiva no segmento mundial. Os principais destinos dos produtos de floricultura cearense são: 70\% vão para Holanda, $20 \%$ vão para os Estados Unidos e $10 \%$ distribuídos em países com Portugal e França. Um dos fatores para que o estado do Ceará ocupe esta posição privilegiada no mercado nacional e internacional, são as condições climáticas favoráveis (AGROINDÚSTRIA TROPICAL, 2010).

Para se garantir um rendimento economicamente viável de uma cultura agrícola principalmente em regiões áridas e semiáridas, a irrigação é indispensável devido ao fato das chuvas não serem suficientes para manter uma umidade no solo (CARVALHO et al., 2012) adequada durante o ciclo da cultura (CARVALHO et al., 2000). Alves et al. (2008) avaliando diferentes níveis de irrigação na cultura da roseira cultivada em ambiente protegido, observaram que as plantas sem estresse hídrico aumentou seu desempenho produtivo em número de hastes por vasos.

Pereira et al. (2003) relatam que a lâmina d'água em excesso pode provocar perdas de água e lixiviação de nutrientes pela percolação abaixo da zona das raízes, favorecer a proliferação de microorganismos patógenos e, em terrenos mal drenados, provocar a saturação do solo. Acrescentam ainda, que a quantidade insuficiente de água proporciona uma redução da reserva útil do solo, prejudicando as plantas, desperdiçando recursos valiosos e aumentando os custos da água aplicada, além de acentuar os problemas relacionados com a salinização do solo.

Já para Taiz e Zeiger (2009) a deficiência hídrica também gera redução da atividade fotossintética, conjuntamente com a diminuição do volume celular e o declínio da turgescência.

O presente trabalho teve como objetivo avaliar os efeitos de diferentes níveis de irrigação nos aspectos produtivos da cultura da roseira (Rosa sp) cultivada em ambiente protegido.

\section{MATERIAL E MÉTODOS}

O trabalho foi conduzido na Empresa CEAROSA Comércio Exportação Importação e 
Produção de Flores LTDA, localizada no Vale dos Buritis, Distrito de Inhuçú, São Benedito, Ceará de coordenadas geográficas $04^{\circ} 07^{\prime} \mathrm{S}$, $40^{\circ} 53^{\prime} \mathrm{W}$ e $886 \mathrm{~m}$ de altitude, no período de setembro a dezembro de 2005.

De acordo com a classificação climática de Köppen (1948), o clima da região é do tipo Am, caracterizado como clima tropical chuvoso, com precipitação total anual superior a 1500 mm, característico de áreas elevadas. Os valores médios mínimos e máximos mensais de temperatura do ar e umidade relativa do ar, registrados durante o experimento no interior do ambiente protegido, podem ser visualizados na Tabela 1.

Tabela 1 - Valores médios de Temperatura e Umidade Relativa do ar

\begin{tabular}{|c|c|c|c|c|c|c|}
\hline \multirow{2}{*}{ Mês } & \multicolumn{3}{|c|}{ Temperatura $\left({ }^{\circ} \mathrm{C}\right)$} & \multicolumn{3}{|c|}{ Umidade Relativa (\%) } \\
\hline & Mínima & Máxima & Média & Mínima & Máxima & Média \\
\hline Outubro & 19 & 36 & 27,5 & 51 & 91 & 71,0 \\
\hline Novembro & 18 & 35 & 26,5 & 54 & 91 & 72,5 \\
\hline Dezembro & 19 & 35 & 27,0 & 56 & 91 & 73,5 \\
\hline
\end{tabular}

O solo da área é classificado como Neossolo Quartzarênico (EMBRAPA, 2006), de textura franco arenosa. Algumas características físicas e químicas do solo foram determinadas antes da aplicação dos tratamentos, podem ser observadas nas Tabelas 2 e 3.
Tabela 2 - Características físicas do solo da área experimental

\begin{tabular}{|c|c|c|c|c|c|c|}
\hline \multirow[t]{3}{*}{ Profundidade } & \multicolumn{4}{|c|}{ Granulométrica } & \multicolumn{2}{|c|}{ Densidade } \\
\hline & $\begin{array}{l}\text { Areia } \\
\text { grossa }\end{array}$ & Areia fina & Silte & Argila & DS & DP \\
\hline & \multicolumn{4}{|c|}{$\mathrm{g} \mathrm{kg}^{-1}$} & \multicolumn{2}{|c|}{$\mathrm{g} \mathrm{cm}^{-3}$} \\
\hline $0,6-0,8(\mathrm{~m})$ & 470 & 340 & 90 & 100 & 13,5 & 2,55 \\
\hline $0,8-1,0(\mathrm{~m})$ & 440 & 340 & 90 & 130 & 1,34 & 2,58 \\
\hline
\end{tabular}

Tabela 3 - Características químicas do solo da área experimental

Parâmetros

Profundidade $0-0,2(\mathrm{~m})$

$\begin{array}{lllllllllll}\mathrm{pH} & \mathrm{MO} & \mathrm{P} & \mathrm{K} & \mathrm{Ca} & \mathrm{Mg} & \mathrm{CTC} & \mathrm{H}+\mathrm{Al} & \mathrm{Na} & \mathrm{Cea}\end{array}$

\begin{tabular}{ccccccccccc}
$\mathrm{CaCl}_{2}$ & $\begin{array}{c}\mathrm{g} \\
\mathrm{dm}^{-3}\end{array}$ & $\begin{array}{l}\mathrm{mg} \\
\mathrm{m}^{-3}\end{array}$ & & & & & $\mathrm{mmol}_{\mathrm{c}} \mathrm{dm}^{-3}$ & & & $\begin{array}{c}\mathrm{dS} \\
\mathrm{m}^{-1}\end{array}$ \\
6 & 21 & 536 & 4,66 & 126 & 15 & 166 & 19 & 2,1 & 2,1 \\
\hline
\end{tabular}

A cultura utilizada no experimento foi a roseira, variedade Iracema. Esta variedade é um híbrido de chá, do tipo decorativo, e é produzida como flor de corte. Apresenta hastes retilíneas e eretas, poucos espinhos, folhas grandes, alternadas, coloração verde escura e opaca, sua flor principal apresenta coloração vermelha, o tamanho do botão varia de médio a grande, de 4,0 a $6,0 \mathrm{~cm}$ de diâmetro, produz hastes de 50 a $80 \mathrm{~cm}$, seu ciclo é de 42 a 45 dias e pode produzir mais de 15 hastes por metro quadrado (Figura 1). 


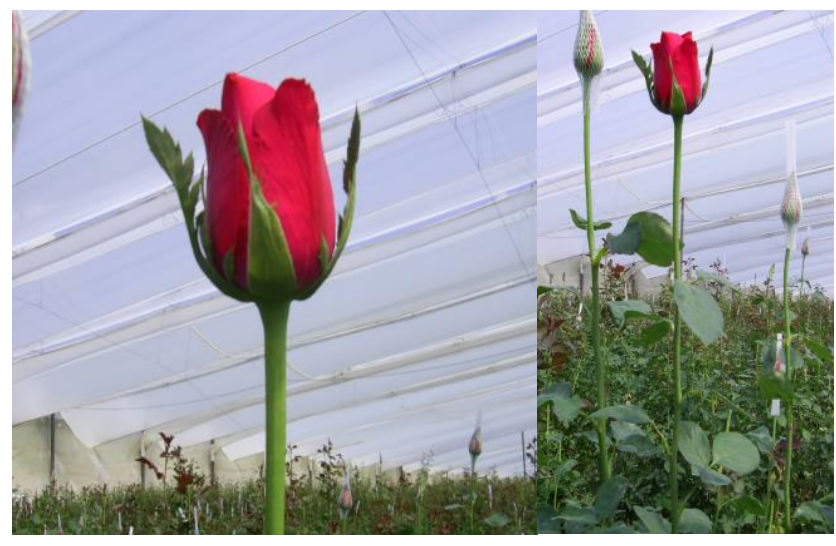

Figura 1 - Variedade "Iracema", São BeneditoCeará.

As mudas, da variedade Iracema, empregadas nessa pesquisa foram obtidas a partir de hastes de rosas sadias, da própria variedade, através do processo de enxertia do tipo garfagem holandesa simples, realizada na própria empresa. As hastes foram cortadas em estacas com aproximadamente $8 \mathrm{~cm}$ de comprimento, imersas em um recipiente com os hormônios ácido indolbutírico (IBA) e ácido naftalênico acético (ANA) e plantadas em bandejas de plástico, com suas células contendo pó de coco seco pré-lavado. Após 30 dias de plantadas nas bandejas, foram transplantadas para os canteiros.

O delineamento experimental utilizado foi em blocos casualizados, composto por cinco tratamentos e quatro repetições. Cada repetição foi composta por 19 plantas, sendo as 15 plantas centrais consideradas úteis, e as quatro restantes serviam de bordadura. O plantio foi realizado no solo, em canteiros com $0,70 \mathrm{~m}$ de altura, no espaçamento de $1,30 \times 0,08 \mathrm{~m}$. As laterais dos canteiros foram protegidas por um plástico do tipo blackwhite de $125 \mathrm{~mm}$.

Os tratamentos consistiram de cinco lâminas de irrigação: 100, 150, 200, 250 e 300\% da evaporação de água observada em um tanque Reduzido (ETR), instalado no interior do ambiente protegido.

O sistema de irrigação utilizado foi por gotejamento, com vazão média de $2 \mathrm{~L}^{-\mathrm{h}^{-1}}$. As diferenciações das lâminas de irrigação, de acordo com os tratamentos, iniciaram no dia 02 de novembro e prosseguiram até o dia 23 de dezembro de 2005.

Aos 21 dias após a diferenciação dos tratamentos, iniciou-se a colheita das hastes comerciais para analisar a produtividade da roseira por ciclo por hectare, de acordo com a classificação estabelecida pela empresa em: Top Quality (TQ) com hastes de 60 e $50 \mathrm{~cm}$ de comprimento, Carmela Diamante (CD) com hastes de 60, 50 e $40 \mathrm{~cm}$ e Carmela Ouro (CO) com hastes de 50 e $40 \mathrm{~cm}$.

As irrigações foram diárias, a partir das leituras do nível da água no tanque, que eram efetuadas sempre às 8 horas, com o auxilio de um parafuso micrométrico instalado no poço tranqüilizador. A partir da lâmina de água evaporada, era calculado o tempo de irrigação (Ti), em minutos (min), utilizando-se a equação 1 para cada tratamento.

$$
\mathrm{Ti}=\frac{\mathrm{EV} \times \mathrm{Ap} \times \mathrm{Fc}}{\mathrm{Ei} \times \mathrm{Q}} \times 60
$$


Em que:

EV - \% de água evaporada, no período de $24 \mathrm{~h}$;

Ap - Área da parcela $\left(\mathrm{m}^{2}\right)$;

Fc - Fator de cobertura, adimensional, sendo considerado igual a 1 ;

Ei - Eficiência de irrigação, adimensional, sendo considerado igual a 0,9 ;

$\mathrm{Q}$ - Vazão na parcela $\left(\mathrm{L} \mathrm{h}^{-1}\right)$.

Durante todo o período de produção, foi realizado o controle fitossanitário das plantas de acordo com o planejamento feito pela própria empresa. As adubações químicas, com macro e micronutrientes, foram realizadas diariamente por meio de fertirrigação, também seguindo o planejamento da empresa.

Os dados foram submetidos à análise de variância utilizando o valor máximo a $5 \%$ de significância para o Teste $\mathrm{F}$ e realizando-se análise de regressão quando ocorreu efeito significativo. Para as análises, foram utilizados os aplicativos Microsoft Office Excel (2003) e SISVAR versão 4.6 (FERREIRA, 2003).

\section{RESULTADOS E DISCUSSÃO}

Os diferentes tratamentos receberam lâminas de irrigação equivalentes durante todo o ciclo produtivo, 42 dias, de 100; 150; 200; 250 e 300\% da evaporação de água observada em um tanque Reduzido (ETR), simbolizado respectivamente, por L1, L2, L3, L4 e L5. A evaporação de água média observada no tanque Reduzido durante o experimento foi de $4,0 \mathrm{~mm} \mathrm{dia}^{-1}$.
Os valores médios relacionados à produtividade da roseira (hastes ha $^{-1}$ ciclo $^{-1}$ ), de acordo com a lâmina de irrigação, com base na evaporação de água observada no tanque Reduzido, encontram-se na Tabela 4. A produtividade da roseira se refere à estimativa do número de hastes úteis produzidas por hectares por ciclo, englobando as hastes dos tipos: Top Quality (TQ), Carmela Diamante (CD) e Carmela Ouro (CO). As hastes úteis foram as que possuem valor comercial, ou seja, que foram para a comercialização. As hastes que apresentavam doenças, atacadas por pragas, defeitos de conformação, foram descartadas, não sendo computadas na estimativa da produtividade.

Tabela 4 - Produtividade da roseira, de acordo com as diferentes lâminas de irrigação.

\begin{tabular}{|c|c|c|}
\hline \multirow{3}{*}{ Tratamentos } & \multirow{3}{*}{$\begin{array}{l}\text { Lâmina } \\
\text { (\%) ETR }\end{array}$} & \multirow{3}{*}{$\begin{array}{c}\text { Produtividade } \\
\left(\text { hastes ha- } \text { ciclo }^{-1}\right)\end{array}$} \\
\hline & & \\
\hline & & \\
\hline L1 & 100 & $207.083 \mathrm{c}$ \\
\hline L2 & 150 & $288.750 \mathrm{~b}$ \\
\hline L3 & 200 & $352.916 \mathrm{ab}$ \\
\hline L4 & 250 & $323.750 \mathrm{a}$ \\
\hline L5 & 300 & $358.750 \mathrm{a}$ \\
\hline DMS & & 38.117 \\
\hline
\end{tabular}

Médias seguidas da mesma letra nas colunas não diferem entre si pelo teste de Tukey $5 \%$.

DMS: diferença mínima significativa.

Pode-se observar na Tabela 4, que os valores médios relacionados à produtividade da roseira (hastes ha ${ }^{-1}$ ciclo $^{-1}$ ), em função da lâmina 
de irrigação, apresentaram diferença significativa, ao nível de $5 \%$ de probabilidade pelo teste de Tukey. Verifica-se que os maiores valores de produtividade foram obtidos com os tratamentos L3, L4 e L5, que correspondem a 200, 250 e $300 \%$ da evaporação de água observada no tanque Reduzido, não havendo diferença estatística entre eles. Em oposição, o menor valor médio da produtividade foi obtido pelo tratamento L1, $100 \%$ da ETR, diferindo estatisticamente ao nível de $5 \%$ de probabilidade dos outros quatro tratamentos.

A produtividade da roseira foi afetada possivelmente pelo fato da menor disponibilidade hídrica provocar problemas de ordem fisiológica, ou seja, provocar efeito negativo no desenvolvimento e produtividade das plantas, enquanto o excesso hídrico ocasiona diminuição na pressão de oxigênio (hipoxia) ou a falta do mesmo (anoxia), dificultando a respiração das plantas e, consequentemente, diminuindo a produção de energia necessária para a síntese e translocação dos compostos orgânicos e absorção ativa dos mesmos (LIETH et al., 2001).

O resultado da análise de regressão da produtividade da roseira (hastes $\mathrm{ha}^{-1}$ ciclo $^{-1}$ ) em função da lâmina de irrigação utilizada pode ser visualizado na Figura 16. A equação de regressão que melhor se ajustou foi a polinomial quadrática, com um coeficiente de determinação $\left(\mathrm{R}^{2}\right)$ de 0,91 , ou seja, $91 \%$ da variação da produtividade da roseira pode ser explicada por essa equação. A lâmina de irrigação corres- pondente ao ponto de inflexão, que proporcionaria a maior produtividade é $263 \%$ da ETR, obtendo-se uma produtividade média de 354.381 hastes ha ${ }^{-1}$ ciclo $^{-1}$.

A redução da produtividade em função da aplicação excessiva de água também foi revelada por Rego et al. (2009), com crisântemo (Dendranthema grandiflora) cultivada em ambiente protegido nas condições climáticas de Guaramiranga, Ceará. Contrariando esse resultado, Alves et al. (2008), avaliando diferentes níveis de irrigação na cultura da roseira, registraram um modelo linear crescente sob os aspectos produtivos.

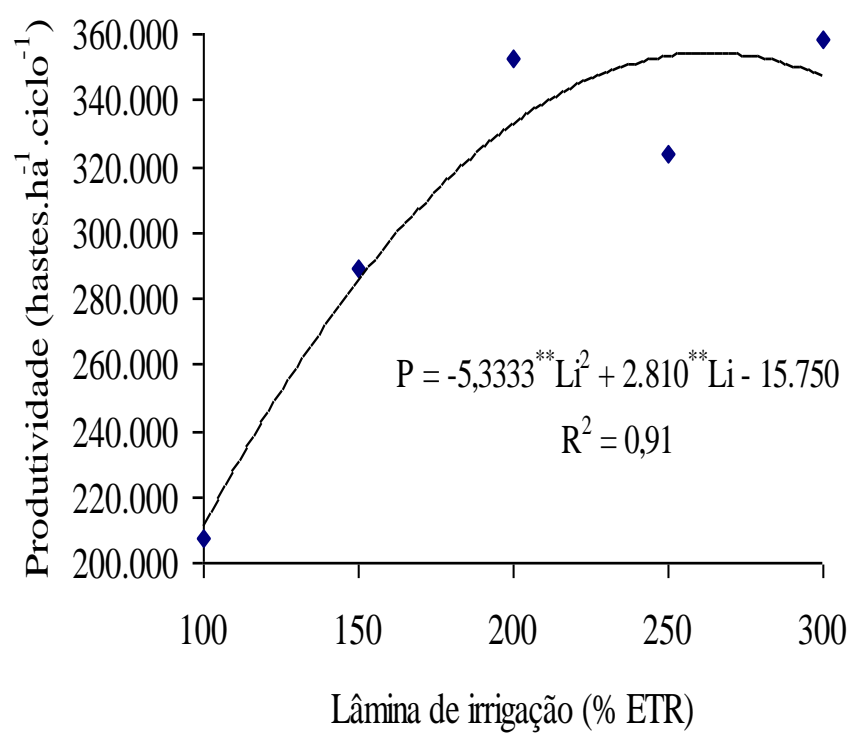

Figura 2 - Produtividade da roseira em função das lâminas de irrigação, São Benedito, Ceará, 2005.

\section{CONCLUSÕES}

Dentre as lâminas de irrigação testadas, a de $200 \%$ da evaporação de água no tanque 
Reduzido foi a menor lâmina que proporciona o maior rendimento da roseira, obtendo-se uma produtividade de 288.750 (hastes ha $^{-1}$ ciclo $^{-1}$ ).

A lâmina de irrigação correspondente a $263 \%$ da evaporação de água no tanque Reduzido foi calculada a máxima produtividade (354.381 hastes ha ${ }^{-1}$ ciclo $^{-1}$ ).

\section{AGRADECIMENTOS}

Os autores agradecem a Empresa de Comercio Exportação Importação e Produção de Flores LTDA (CEAROSA) e ao CNPq pelo suporte financeiro.

\section{REFERÊNCIAS BIBLIOGRÁFICAS}

Agência de Desenvolvimento do Estado do Ceará. Exportações do Ceará no ano de 2010, com foco no agronegócio. Disponível em: $<$ http://www.adece.ce.gov/downloads/agronego cio/exportacoescearenses10_PP.pdf.>. Acessado em : 19 jun. 2012.

ALVES, A. M.; VIANA, T. V. A.; AZEVEDO, B. M.; JOVINO, M. R. M.; FURLAN, R. A. Efeitos de níveis de irrigação sobre a cultura da rosa. Irriga, v.13, n.2, p.152-159, 2008.

BAÑON ARIAS, S.; CIFUENTES ROMO, D.; HERNANDEZ, J.A.F.; BENEVENTEGARCIA, A. La Rosa. In: BAÑON ARIAS, S.; CIFUENTES ROMO, D.; HERNANDEZ, J.A.F.; BENEVENTE-GARCIA，A. Gérbera, Lilium, Tulipán y Rosa. Madrid: MundiPrensa, 1993, cap.4, p.202-250.

BARBOSA, J.G. Produção Comercial de Rosas. Viçosa: 2003, 200 p.
CARVALHO, A. J. et al. Adubação nitrogenada e irrigação no maracujazeiro amarelo: produtividade e qualidade dos frutos. Pesquisa Agropecuária Brasileira, v. 35, n. 6, p. 11011108, junho. 2000.

CARVALHO, C. M.; VIANA, T. V. A.; MARINHO, A. B.; LIMA JÚNIOR, L. A.; MANOEL VALNIR JÚNIOR, M. V.; CORREIA, K. G. Manejo da irrigação e uso de tensímetros digitais no monitoramento do potencial matricial de água no solo em área de pinhão manso irrigado. Revista Brasileira de Agricultura Irrigada v.6, n, 2, p. 115 - 126, 2012.

EMBRAPA - Empresa brasileira de pesquisa agropecuária. Sistema brasileiro de classificação de solos. 2. ed. Rio de Janeiro: Embrapa solos, 2006. 306p.

FERREIRA, D. F. Sisvar, Versão 4.6 (Build 6.0) DEX/FLA. 2003. Disponível em: <http://www.dex.ufla.br/ danielff/prog.htm>. Acessado em: 05 nov. 2005.

GAVIOLI, F. Brasil Prospecta Aumentar Exportação de Flores e Plantas Ornamentais. 2004. Disponível em: <http://netmarinha.uol.com.br/notícias.asp?id=4 $620 \&$ texto $=$ floricultura $>$ Acesso em: 13 mai. 2006.

KOPPEN, W. Climatologia: versão para o espanhol de Pedro R. Hendrichs Pérez. México, Fundo de Cultura Econômica. 1948. p.466p.

LIETH, J. H.; KIM, S. H. Effects of shootbending in relation to root media on cut flower production in roses. Acta Horticulturae, n.547, p.303-310, 2001.

MAIA, A. A.; VIANA, T. V. A.; AZEVEDO, B. M. DE.; JOVINO, M. R. M.; FURLAN, R. R. Efeitos de níveis de irrigação sobre a cultura da rosa. Irriga, v.13. n.2, p.152-159, 2008. 
PEREIRA, J.R.D., CARVALHO, J.A., MIGUEL, D.S. Consumo de água pela cultura do crisântemo cultivado em ambiente protegido. Ciência Agrotécnica, v. 27, n. 3, p. 658 - 664, 2003.

RÊGO, J. L. Efeitos de níveis de irrigação na cultura do crisântemo. 2004. 55 p. Dissertação (Mestrado em Irrigação e Drenagem) Universidade Federal do Ceará, Fortaleza.

RÊGO, J. L.; VIANA, T. V. A.; AZEVEDO, B. M.; ARAÚJO, W. F.; FURLAN1, R. A.;
BASTOS, F; G; C. Produtividade de crisântemo em função de níveis de irrigação, Horticultura Brasileira, v.27, p. 045-048, 2009.

TAIZ, L.; ZEIGER, E. Plant Physiology. 5. ed. Sunderland: Sinauer Associates,Inc.,2010.782 p.

TOMÉ, L. M. Avaliação do Desempenho Logístico-Operacional de Empresas no Setor da Floricultura: Um Estudo de Caso no Ceará. 2004. p. 163. Dissertação de Mestrado, Programa de Mestrado em Engenharia de Transportes, Universidade Federal do Ceará, Fortaleza. 